\title{
Corporate Sustainability Disclosure: A Leather Industry Perspective
}

\author{
Oluwaseyi Omoloso ${ }^{\mathrm{a}} \mathrm{b}^{*}$, William R. Wise ${ }^{\mathrm{a}}$, Kathleen Mortimer ${ }^{\mathrm{b}}$, Luai Jraisat ${ }^{\mathrm{b}}$ \\ ${ }^{a}$ Institute for Creative Leather Technologies, University of Northampton, University Drive, Northampton, NN1 5PH, United Kingdom \\ ${ }^{b}$ Faculty of Business and Law, University of Northampton, Northampton, NN1 5PH, United Kingdom
}

\begin{abstract}
This study aims to identify and compare the key social, economic and environmental sustainability practices in the leather industry. Content analysis was used to analyse extracted sustainability information from either the website, annual report, sustainability report or corporate social responsibility report of six leather-related companies. Review of existing literature assisted in categorising different practices under social, economic and environmental sustainability, while an identification of patterns among practices followed. Findings reveal that companies are observing a good practice of either dedicating a section of their website to revealing their sustainability activities or utilising their sustainability reports or annual reports. Energy efficiency, waste management and reduction of greenhouse gases emission were the most occurring environmental sustainability practices. Health and safety occurred as the dominant social sustainability practice, while economic sustainability practices have not been well defined, providing an opportunity for future research. The study provides a useful resource for managers and companies in the leather supply chain to learn from brands that have been embarking on sustainability efforts and assist them to a better understanding of the concept, in readiness for strategy formulation, implementation and reporting.
\end{abstract}

\section{Keywords:}

Sustainability Reporting;

Leather Industry;

Environmental;

Economic;

Social.

Article History:

Received: 02 December 2019

Accepted: 23 January 2020

Published: $01 \quad$ February 2020

\section{1- Introduction}

Over the years, the subject of sustainability reporting has gained prominence in industrial contexts. Previously, the need for sustainability actions and reporting was borne out of the need to meet legal and regulatory compliances. Now, business stakeholders such as suppliers, customers and investors are the main drivers for the communication of sustainability credentials [1-3]. Furthermore, being transparent about revealing sustainability credentials has also been a source of competitive advantage for businesses [4]. This study focuses on the leather industry, where present literature on sustainability has often significantly focused on the environmental aspect, with social and economic sustainability aspects having gained less attention.

Few studies relating to sustainability reporting in the leather industry exist. Śmiechowski and Lament (2017) revealed the "impacts of CSR reporting on pro-ecological actions of large and small tanneries" but does not delve into the specificity of what is contained in the reports of companies surveyed in their study [5]. It was noted that sustainability reports and reporting play a crucial role in improving the understanding of sustainability amongst companies [6]. Thus, this paper proceeds from the above perspective, owing to the need for a long-established industry, like leather, with a complex global supply chain and presence of several small and medium enterprises to understand the practices relating to the sustainability dimensions.

Several authors have discussed different topics relating to sustainability reporting but none of the previous studies have made a comparison between companies on how reporting is done and what is being reported, in the context of the leather industry. Hence, the aim of this study is to identify and compare the key social, economic and environmental

* CONTACT: Oluwaseyi.omoloso@ northampton.ac.uk

DOI: http://dx.doi.org/10.28991/esj-2020-01209

(C) 2019 by the authors. Licensee ESJ, Italy. This is an open access article under the terms and conditions of the Creative Commons Attribution (CC-BY) license (https://creativecommons.org/licenses/by/4.0/). 
sustainability practices in the leather industry, using the sustainability reports of selected leather-based companies. This paper contributes to the literature in a major way - it focuses on a 'sustainability-sensitive' industry like leather where sustainability reporting is crucial but understudied, compared to other industries.

\section{2- Literature Review}

Leather is regarded as a sustainable material on its own. Contrary to belief that animals are reared for leather use, the leather industry could be seen as one that performs a circular economy function to upcycle the waste (hides and skin) generated from the meat and dairy industries [7, 8]. Hides and skins are collected from slaughter houses after animals have been slaughtered and then usually salted or frozen, in readiness to be transported to tanneries, where they are processed into leather. Collecting these wastes (hides and skin) that serve as the main raw material for the leather industry, also potentially reduces potential landfill dumping of animal hides [9], thus reinforcing the "circular economy industry" nature of leather. However, the tannery processes are characterised by the use of significant quantities of chemicals, energy and water [10-12] and could be labour or capital intensive, depending on the regions of the world and level of technology and or innovation. Solid and liquid wastes are also discharged, which if not properly treated or managed, could pose serious environmental, social and economic issues. As a result, research to improve the sustainability of the industry processes has continued to proliferate.

The "planet" aspect of sustainability, known as environmental sustainability, is based on the notion that for humans to continually enjoy the ecosystem services the environment provides (such as renewable and non-renewable resources and capacity for waste absorption), there is a need to live within the boundaries of "biophysical environment" [13]. The leather industry, characterised by its high volume of solid and liquid effluents takes the issue of environmental sustainability seriously [14]. In fact, if adequate environmental management systems are not installed, the tanning industry could pose a threat, both environmentally and socially, due to the chemical intensive production processes, energy consumption and solid and liquid wastes [5]. Considering this as a stand-alone factor necessitates the importance of revealing how leather-related companies are (and can) practically gearing efforts towards being environmentally friendly, socially responsible and economically viable. Indeed, recent studies and topics in the environmental sustainability domain of the industry include pollution prevention and control [12, 15], materials life cycle analysis [8], green chemistry approaches $[16,17]$, waste management and circular economy [18] and sustainable manufacturing [19, $20]$.

On the other hand, social sustainability, also known as the "people" aspect of sustainability is often regarded as the least explored dimension of sustainability and is characterised by discussions relating to health and safety, diversity and equal opportunities, employee training and remuneration, basic needs etc. [21, 22]. Owing to the labour-intensive nature of the leather industry [23] and the multiplier effects that poor environmental practices could have on employees, community and customers, social sustainability is an important area to address. For example, previous studies in social sustainability have been firmly on health and safety, especially in tanneries [24-26], where hides and skins are converted to leather using various chemicals. These studies revealed that people of both genders, working in the tanning industry, have an increased risk of developing some form of cancer or other terminal diseases during their lifetime, if protective measures are inadequate [24-27]. This suggests a dire need for actors to take the issue of occupational and community health and safety as crucial. Intuitively, only healthy work and happy workers could adequately contribute to the economic or environmental sustainability of a company or industry over the long run.

Economic sustainability, also referred to as the "profit" dimension takes into consideration an organisation's effort to improve the value it generates and delivers to its customers, at the same time reducing the cost of its supply chain related activities [28]. In the context of the leather industry, studies relating to economic sustainability have usually been found in topics relating to customer perceptions and sustainable behaviours when making buying choices [29,30]. Additionally, in becoming economically sustainable, organisations are suggested to gear considerable efforts towards making maximum profit while ensuring the most efficient use of all resources and raw materials [31]. The International Council of Tanners (ICT), an organisation of world's leather trade associations defines the elements of the three sustainability aspects for the leather industry as shown in Table 1Error! Reference source not found..

Table 1. Leather Sustainability practices [32]

\begin{tabular}{llll}
\hline \multicolumn{1}{c}{ Environmental sustainability } & \multicolumn{1}{c}{ Social sustainability } & Economic sustainability \\
\hline $\begin{array}{l}\text { Complete compliance with environmental regulations that } \\
\text { encapsulates water, air emissions, and solid waste. }\end{array}$ & $\begin{array}{l}\text { Complete compliance with product safety } \\
\text { regulations. }\end{array}$ & $\begin{array}{l}\text { Commitment to fair trade } \\
\text { practices. }\end{array}$ & Traceability of raw material hides. \\
\hline Obligation to energy efficiency. & Health and safety compliance. & $\begin{array}{l}\text { Observing and promoting correct } \\
\text { labelling of leather and its } \\
\text { products. }\end{array}$ \\
\hline $\begin{array}{l}\text { Life Cycle Assessment (LCA) identification, } \\
\text { environmental footprint of the leather industry. }\end{array}$ & $\begin{array}{l}\text { Compliance with employers' regulations (e.g. } \\
\text { human rights) }\end{array}$ & $\begin{array}{l}\text { Transparency on origin of leather } \\
\text { production. }\end{array}$ \\
\hline $\begin{array}{l}\text { Application of best practices during processing to } \\
\text { anticipate future environmental controls and carbon } \\
\text { footprint reduction. }\end{array}$ & $\begin{array}{l}\text { Commitment to the principles of animal } \\
\text { welfare. }\end{array}$ & &
\end{tabular}


The table provides a comprehensive and useful insight into what being sustainable depicts, in terms of the leather industry and could serve as a basis of comparison to what is being reported by leather companies. The act/art of companies disclosing their sustainability activities and progress is usually regarded as sustainability reporting [1, 6, 33].

Sustainability reporting is described as a voluntary activity that has become prominent among business enterprises $[2,5]$. Though a voluntary endeavour, its adoption is seeing exponential growth by organisations across the globe [4]. It was reported that three quarters of 4900 (large and middle-sized) companies studied now issue corporate responsibility reports [34]. Also, given the recent EU directive 2014/95/EU that necessitates corporations (with at least 500 employees) to disclose information relating to their sustainability credentials [35], it can be argued that in the near future, the practice of reporting could become a necessity for small, medium and large companies. Furthermore, in different organisational contexts, sustainability reporting has been similarly referred to corporate social responsibility (CSR) reporting, triple bottom line reporting, non-financial reporting, sustainable development reporting, environmental, social and governance (ESG) reporting $[1,4]$. However, sustainability reporting is pragmatically used in this study as it conforms to the subject under discussion.

Sustainability reporting has been identified to provide organisations with several benefits. Such benefits include contribution to the enhancement of organisations' reputation, thereby attracting investors [5, 34]. Additionally, it was argued that reporting drives value and companies preparing reports manage liquidity better than their counterparts who do not [36]. However, research in this area in the industry context under discussion is scant, highlighted by only one previous that defined the impact of CSR reporting on pro-ecological actions of large and small tanneries [5]. This present study builds on the previous key research by providing clarity on the sustainability activities that represent the focus of companies. Understanding the practical aspect of sustainability in the leather industry context in relation to the three sustainability dimensions could enable related organisations to reap the possible benefits and potentially increase the understanding of the three dimensions in the industry.

\section{3- Materials and Methods}

To achieve the aim of the research, secondary data in form of the sustainability/CSR reports or statements of six leather-related companies were used. These companies were purposely selected based on the criteria that they are involved in some form of sustainability actions and there is ease of access to their CSR/Sustainability report or statements. The content analysis method was used to analyse the contents of these reports because of its suitability for analysing information from documents [37]. This approach was also followed in similar studies [38-40]. Content analysis is defined as the "systematic reading of a body of texts, images and symbolic matter, not necessary from an author's or user's perspective" [41]. The reports were carefully examined to extract word clusters that suitably explain the constituents of their efforts in relation to the three sustainability dimensions. The identity of the companies used in the study was also anonymised.

The nature of sustainability concept requires that an understanding of contextual meanings and phrases are taken into consideration in order to extract necessary information. Hence, human coding method was used. Additionally, human coding is appropriate for small volumes of data [42] and in this case, six sustainability reports/websites were reviewed as shown in Table 2 .

Table 2. Distribution of reports by publication year

\begin{tabular}{cc}
\hline Company & Year of Report \\
\hline Tannery A & 2018 \\
Tannery B & 2017 \\
Tannery C & 2019 \\
Manufacturing A & 2018 \\
Manufacturing B & 2017 \\
Manufacturing C & 2017 \\
\hline
\end{tabular}

Latent and manifest analysis i.e. what is evident and obvious from the reports as well as underlying meanings from textual data from the reports [43], were the approaches to analysis. Thus, the unit of analysis is the words or group of words that state each sustainability practice. Furthermore, the "emergent" method of coding was used rather than the "a priori" method [44]. This meant the categories of words coded were identified after carefully reading through the sustainability reports or statements to identify key words or group of words related to the three sustainability dimensions. Existing literature was used to verify the efficacy of the coding categories. 


\section{4- Results and Discussion}

Results show that companies have a range of channels through which they publish their sustainability efforts as shown in Figure 1. While some companies published separate sustainability reports apart from their annual reports, some other companies have adopted an integrated approach of including their sustainability activities within their annual report without publishing a separate sustainability report. The latter is called integrated reporting, and represents one of the growing trends of sustainability reporting [34]. Websites also represent a medium of reporting.

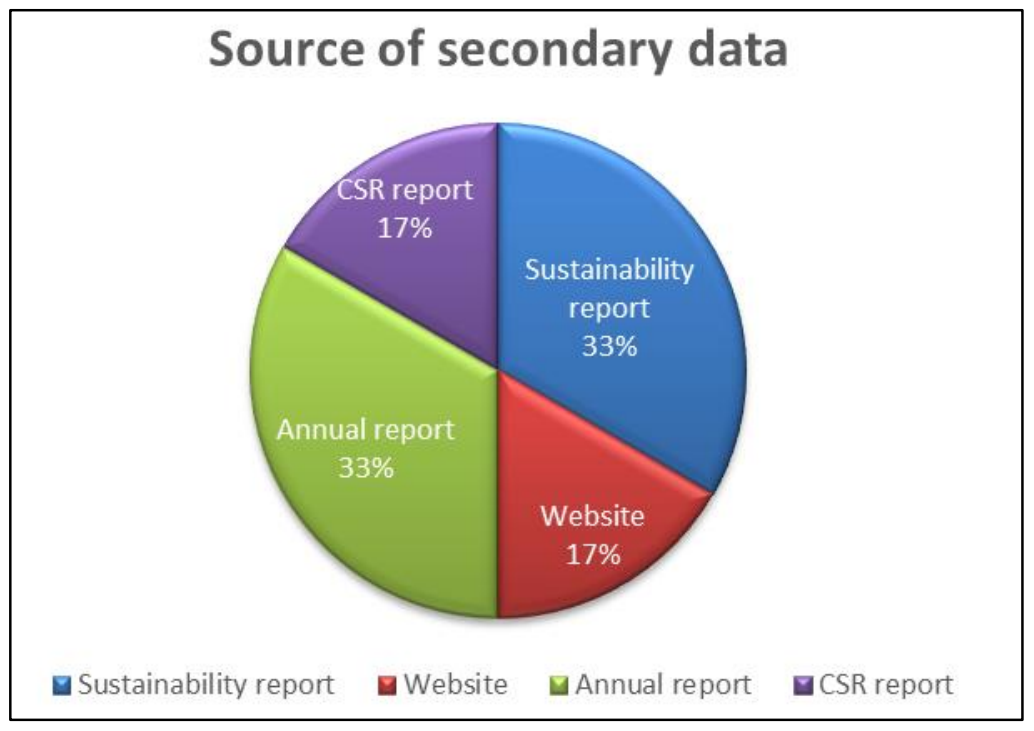

Figure 1. Distribution of data analysed by source

The latest report (as at compilation of this research manuscript) from these organisations was selected and practices from the three sustainability dimensions were carefully identified and results presented in Table 3 below:

Table 3. Comparison of leather companies on practices relating to the sustainability dimensions

\begin{tabular}{|c|c|c|c|c|c|c|}
\hline \multirow{2}{*}{ Coding Categories } & \multicolumn{6}{|c|}{ List of Companies - Tan $=$ Tannery $;$ Man $=$ Manufacturing } \\
\hline & $\operatorname{Tan} \mathbf{A}$ & Tan B & Tan C & $\operatorname{Man} \mathbf{A}$ & Man B & Man C \\
\hline \multicolumn{7}{|c|}{ Environmental sustainability practices } \\
\hline Energy Efficiency & o & o & o & o & o & o \\
\hline Emission reduction of greenhouse gases & o & o & o & o & o & o \\
\hline Efficient water management & o & o & & o & o & o \\
\hline Waste Management & $\circ$ & o & ० & $\circ$ & $\circ$ & $\circ$ \\
\hline LCA Assessment identification & & ० & & & o & o \\
\hline Reduced noise and olfactory emissions & & & & & o & \\
\hline \multicolumn{7}{|c|}{ Social Sustainability practices } \\
\hline Health and safety & $\circ$ & $\circ$ & $\circ$ & o & $\circ$ & $\circ$ \\
\hline Employee development & ० & $\circ$ & & $\circ$ & ० & $\circ$ \\
\hline Diversity and equal opportunities at the workplace & o & o & & o & o & o \\
\hline Respect and protection of human/workers' rights & $\circ$ & $\circ$ & & $\circ$ & $\circ$ & $\circ$ \\
\hline Local community engagement & ○ & o & & o & o & o \\
\hline Work-life balance & ○ & $\circ$ & & & ० & $\circ$ \\
\hline Job security & & $\circ$ & & & & $\circ$ \\
\hline No use of forced or child labour & o & o & & o & $\circ$ & o \\
\hline Animal welfare & o & ○ & & & o & \\
\hline \multicolumn{7}{|c|}{ Economic Sustainability practices } \\
\hline Investment in innovative technologies & $\circ$ & $\circ$ & & & & \\
\hline Traceability of raw skin and hides & $\circ$ & ○ & & ○ & & ○ \\
\hline Efficiency of resource use & & o & ० & & & o \\
\hline Profitability & & $\circ$ & o & & & \\
\hline
\end{tabular}


The analysis indicated that some companies state their holistic approach towards sustainability. For example, in Tannery A, what sustainability means to the company was well captured in a statement in their sustainability report:

"Sustainability is not just about continuing business as usual. Rather, it is an evolution towards a sustainable future in which environmental priorities, economic prosperity and social justice are pursued simultaneously".

Similarly, in Tannery B, a holistic approach towards sustainability is captured on their website as thus:

\author{
"Achieving sustainability means bringing the environmental, financial, and social aspects of our commercial \\ operations together in a permanently balanced and harmonious relationship"
}

These clear statements suggest how crucial the focus on the three sustainability aspects is, rather than a focus on just one aspect. However, it is important to note that failure of companies to indicate some practices in their report does not necessarily mean an absence of these practices, more so, since the absence of a sustainability report does not translate to the absence of sustainability practices [5]. Furthermore, it was revealed that some brands use the concept of sustainability and CSR interchangeably, conforming to related literature [1, 4].

The findings reveal that energy efficiency, waste management and reduction in greenhouse gases emission represented the most reported environmental sustainability practices, occurring in all the analysed reports. Efficient water management and evaluation of the environmental footprint of activities (in form of LCA identification) were other key practices. The uniformity of practices among these actors suggests a sound understanding of environmental sustainability among the organisations. This finding reflects with the literature on the prevalence and dominant focus on the environmental aspect.

With regards to social sustainability, health and safety occurred in all the reports analysed. The authors posit that this could be because of the nature of the industry. Additionally, in five of six companies, employee development; diversity and equal opportunities at the workplace; respect and protection of human/workers' rights; local community engagement and compliance to labour regulations (in form of no use of forced or child labour) featured as important social sustainability practices. Work-life balance was also a point of emphasis in four of the companies. While animal welfare was also deemed as an important practice, it should be understood that the leather industry does not take responsibility for the impacts of animal rearing (an agricultural activity) in relation to sustainability [45]. Nevertheless, some companies seek to ensure that their relevant upstream supply chain partners treat animals with utmost care. Conclusively, the recurrence of these practices amongst the companies suggests a good level of awareness and understanding of the social dimension of sustainability.

Finally, traceability of the raw materials used in production of the leather products is the most recognised economic practice. Traceability is a crucial aspect of the leather supply chain, as some of the regulating bodies and associations [like the Leather Working Group (LWG) and Confederation of National Associations of Tanners and Dressers of the European Community (COTANCE)] constantly push for transparency on the origin of hides and skin and other raw materials to improve the image of the leather industry [9]. Efficiency of resource use (an important economic problem due to scarcity) was also highlighted in half of the reports analysed, as an important consideration. This factors into some important initiatives related to resource efficiency like the United Nations Environment Programme [46] and part of Europe 2020's strategy called "Resource-efficient Europe" [47]. Lastly, profitability (a traditional business indicator that reflects the health of a business) and investment in innovative technologies least featured. Largely, economic sustainability practices were found to be dissimilar and under-reported. In fact, there appears to be a non-convergence on the areas of focus on economic sustainability practices when compared to the environmental and social aspects. Hence, future research to investigate the causes of disparity in focus may be necessary to set the foundation for unification on related practices.

To reiterate, companies not highlighting specific practices in their reports or website does not necessarily mean an absence. For example, the statement of Tannery $\mathrm{C}$ focuses significantly on their environmental responsibility efforts. However, this does not translate that they are not making efforts relating to economic and social sustainability, since the company falls under the EU directive previously mentioned. An absence of a sustainability report may thereby be a reason for under-expression of their sustainability credentials.

Conclusively, the recent trends suggest that companies should publish some form of report that succinctly explains their sustainability efforts, as this information is increasingly demanded by investors, among other business stakeholders [34]. The understanding of these practices is useful because the brands used in this study are well known in their supply chain and thus, could have significant level of control in terms of urging their global supply chain partners towards more sustainable business practices.

\title{
5- Conclusion and Recommendation
}

The importance of sustainability in the leather industry has continually increased over time but in practice, there is a need to foster the holistic understanding of this concept in the supply chain as a significant focus has been on the 
environmental aspect. This paper attempted to uncover some of the practices relating to the dimensions of sustainability, providing a useful resource for actors in the leather supply chain. This study is part of a larger study that broadly focuses on social and economic sustainability in the leather supply chain.

The study has its limitations. The companies whose reports were analysed are all Europe based and fall under the EU directive 2014/95/EU. Hence, the results from this research may not reflect the practices in other non-European countries. Future research may investigate the practices in leather-related companies in other countries for comparative purposes. The data analysed in this study was obtained solely from the company reports and as such, the "face value" of information acquired was adopted but not backed up with primary research. Thus, the validity of findings could be reduced. While this research focuses on particular organisations in different supply chain levels, the transcendence of practices among their supply chain partners can also be investigated to identify best practices and gaps in order to ensure a sustainable leather supply chain.

The findings from this study could assist managers in leather-related companies to better integrate the information on the three sustainability dimensions into their sustainability strategy which could allow for a multiplier effect on better sustainability credentials of actors in the leather supply chain. Furthermore, while metrics usually exist to measure environmental and economic sustainability, the social aspect still suffers from the use of limiting qualitative metrics, such as "yes and no" that does not reveal the true extent of progress. Further research could delve into developing robust metrics which could be qualitative or quantitative in nature and specific to the leather industry. Given the global nature of the leather supply chain, some form of regularised standards could be instituted to ensure the uniformity of sustainability reports in the global industry.

\section{6- Funding and Acknowledgments}

This research was funded by the Faculty of Business and Law (FBL) in collaboration with the Institute for Creative Leather Technologies (ICLT) at the University of Northampton. The authors acknowledge this funding gratefully.

\section{7- Conflict of Interest}

The author declares that there is no conflict of interests regarding the publication of this manuscript. In addition, the ethical issues, including plagiarism, informed consent, misconduct, data fabrication and/or falsification, double publication and/or submission, and redundancies have been completely observed by the authors.

\section{8- References}

[1] Thijssens, Thomas, Laury Bollen, and Harold Hassink. "Managing Sustainability Reporting: Many Ways to Publish Exemplary Reports.” Journal of Cleaner Production 136, (November 2016): 86-101. doi:10.1016/J.JCLEPRO.2016.01.098.

[2] Braam, Geert J. M., Lisanne Uit de Weerd, Mara Hauck, and Mark A. J. Huijbregts. "Determinants of Corporate Environmental Reporting: The Importance of Environmental Performance and Assurance.” Journal of Cleaner Production 129, (August 2016): 724-734. doi:10.1016/J.JCLEPRO.2016.03.039.

[3] Nobanee, Haitham, and Nejla Ellili. "Corporate Sustainability Disclosure in Annual Reports: Evidence from UAE Banks: Islamic Versus Conventional.” SSRN Electronic Journal (May 2016). doi:10.2139/ssrn.2970191.

[4] Siew, Renard Y. J. "A Review of Corporate Sustainability Reporting Tools (SRTs).” Journal of Environmental Management 164, (2015): 180-195. doi:10.1016/j.jenvman.2015.09.010.

[5] Śmiechowski, Krzysztof, and Marzanna Lament. "Impact of Corporate Social Responsibility (CSR) Reporting on pro-Ecological Actions of Tanneries.” Journal of Cleaner Production 161, (September 2017): 991-999. doi:10.1016/j.jclepro.2017.05.104.

[6] Higgins, Colin, and Brian Coffey. "Improving How Sustainability Reports Drive Change: A Critical Discourse Analysis." Journal of Cleaner Production 136, (November 2016): 18-29. doi:10.1016/J.JCLEPRO.2016.01.101.

[7] Dixit, Sumita, Ashish Yadav, Premendra D. Dwivedi, and Mukul Das. "Toxic Hazards of Leather Industry and Technologies to Combat Threat: A Review.” Journal of Cleaner Production 87, (January 2015): 39-49. doi:10.1016/J.JCLEPRO.2014.10.017.

[8] Joseph, Kurian, and N. Nithya. "Material Flows in the Life Cycle of Leather." Journal of Cleaner Production 17, no. 7 (May 2009): 676-682. doi:10.1016/j.jclepro.2008.11.018.

[9] MVO Nederland. "Sustainability in the Leather Supply Chain". Ernst \& Young. (2013).

[10] Selvaraj, Sowmya, Vigneshwar Jeevan, Raghava Rao Jonnalagadda, and Nishter Nishad Fathima. "Conversion of Tannery Solid Waste to Sound Absorbing Nanofibrous Materials: A Road to Sustainability.” Journal of Cleaner Production 213, (March 2019): 375-383. doi:10.1016/j.jclepro.2018.12.144.

[11] Zuriaga-Agustí, E., M. V. Galiana-Aleixandre, A. Bes-Piá, J. A. Mendoza-Roca, V. Risueño-Puchades, and V. Segarra. "Pollution Reduction in an Eco-Friendly Chrome-Free Tanning and Evaluation of the Biodegradation by Composting of the Tanned Leather Wastes.” Journal of Cleaner Production 87, (January 2015): 874-881. doi:10.1016/j.jclepro.2014.10.066. 
[12] Kanagaraj, J., T. Senthilvelan, R. C. Panda, and S. Kavitha. "Eco-Friendly Waste Management Strategies for Greener Environment towards Sustainable Development in Leather Industry: A Comprehensive Review.” Journal of Cleaner Production 89, (February 2015): 1-17. doi:10.1016/J.JCLEPRO.2014.11.013.

[13] Moldan, Bedřich, Svatava Janoušková, and Tomáš Hák. "How to Understand and Measure Environmental Sustainability: Indicators and Targets." Ecological Indicators 17, (June 2012): 4-13. doi:https://doi.org/10.1016/j.ecolind.2011.04.033.

[14] Daniels, Richard, and Walter Landmann. "The Framework for Leather Manufacture.". World Trades Pub, (2013).

[15] Kumar Gupta, Sandeep, Sanjeev Gupta, and S. Gayathiri. “'Pollution Prevention' Is the Key to Drive Sustainability: Preliminary Findings from a Tannery Unit in India.” Management of Environmental Quality: An International Journal 29, no. 3 (2018): 416-426. doi:10.1108/MEQ-10-2017-0124.

[16] Sathish, Murali, Balaraman Madhan, Kalarical Janardhnan Sreeram, Jonnalagadda Raghava Rao, and Balachandran Unni Nair. “Alternative Carrier Medium for Sustainable Leather Manufacturing - a Review and Perspective." Journal of Cleaner Production 112, (2016): 49-58. doi:https://doi.org/10.1016/j.jclepro.2015.06.118.

[17] Krishnamoorthy, G., S. Sadulla, P. K. Sehgal, and Asit Baran Mandal. "Green Chemistry Approaches to Leather Tanning Process for Making Chrome-Free Leather by Unnatural Amino Acids.” Journal of Hazardous Materials 215-216, (May 2012): 173-182. doi:10.1016/J.JHAZMAT.2012.02.046.

[18] Gupta, Sandeep Kumar, and Sanjeev Gupta. "Closed Loop Value Chain to Achieve Sustainable Solution for Tannery Effluent." Journal of Cleaner Production 213, (March 2019): 845-846. doi:10.1016/j.jclepro.2018.12.240.

[19] Dwivedi, Ashish, Dindayal Agrawal, and Jitender Madaan. "Sustainable Manufacturing Evaluation Model Focusing Leather Industries in India: A TISM Approach.” Journal of Science and Technology Policy Management 10, no. 2 (June 2019): 319359. doi:10.1108/JSTPM-06-2018-0054.

[20] Bacardit, Anna, Grau Baquero, Silvia Sorolla, and Luis Ollé. "Evaluation of a New Sustainable Continuous System for Processing Bovine Leather." Journal of Cleaner Production 101, (2015): 197-204. doi:https://doi.org/10.1016/j.jclepro.2015.04.012.

[21] Rasouli, Aso Haji, and Anoma Kumarasuriyar. "The Social Dimention of Sustainability: Towards Some Definitions and Analysis.” 4, no. 2 (2016): 23-34. doi:10.15640/10.15640/jsspi.v4n2a3.

[22] Popovic, Tamara, Ana Barbosa-Póvoa, Andrzej Kraslawski, and Ana Carvalho. "Quantitative Indicators for Social Sustainability Assessment of Supply Chains." Journal of Cleaner Production 180, (April 2018): 748-768. doi:10.1016/J.JCLEPRO.2018.01.142.

[23] ILO. Textiles, Clothing, Leather and Footwear Sector. Available online: http://www.ilo.org/global/industries-andsectors/textiles-clothing-leather-footwear/lang--en/index.htm. (Accessed on May 8, 2018).

[24] Garai, Joydeb. "Environmental Aspects and Health Risks of Leather Tanning Industry: A Study in the Hazaribag Area." Chinese Journal of Population Resources and Environment 12, no. 3 (July 2014): 278-282. doi:10.1080/10042857.2014.910875.

[25] Munny, Azmina Akter, Syed Mithun Ali, Golam Kabir, Md. Abdul Moktadir, Towfique Rahman, and Zuhayer Mahtab. "Enablers of Social Sustainability in the Supply Chain: An Example of Footwear Industry from an Emerging Economy." Sustainable Production and Consumption 20, (October 2019): 230-242. doi:10.1016/j.spc.2019.07.003.

[26] Decouple, Pierre. "Cancer Risks Associated with Employment in the Leather and Leather Products Industry." Archives of Environmental Health: An International Journal 34, no. 1 (January 2013): 33-37. doi:10.1080/00039896.1979.10667364.

[27] Syed, Madiha, Taimur Saleem, Shuja-ur-Rehman Shuja-ur-Rehman, Muhammed Asif Iqbal, Faisal Javed, Muhammed Bilal Salman Khan, and Kamran Sadiq. "Effects of Leather Industry on Health and Recommendations for Improving the Situation in Pakistan.” Archives of Environmental \& Occupational Health 65, no. 3 (July 2010): 163-172. doi:10.1080/19338241003730895.

[28] Closs, David J., Cheri Speier, and Nathan Meacham. "Sustainability to Support End-to-End Value Chains: The Role of Supply Chain Management.” Journal of the Academy of Marketing Science 39, no. 1 (February 2011): 101-116. doi:10.1007/s11747010-0207-4.

[29] de Klerk, Helena M., Madelein Kearns, and Mike Redwood. "Controversial Fashion, Ethical Concerns and Environmentally Significant Behaviour: The Case of the Leather Industry.” International Journal of Retail and Distribution Management 47, no. 1 (January 2019): 19-38. doi:10.1108/IJRDM-05-2017-0106.

[30] Dekhili, Sihem, Mohamed Akli Achabou, and Fatmah Alharbi. "Could Sustainability Improve the Promotion of Luxury Products?” European Business Review 31, no. 4 (June 2019): 488-511. doi:10.1108/EBR-04-2018-0083.

[31] Singh, Satish Chandra, and Dhananjai Gupta. "Sustainability: A Challenge for Indian Leather Industry.” Journal of Supply Chain Management Systems 2, no. 4 (2013): 37-43. 
[32] International Council of Tanners. Sustainability of the Tanning Industry | ICT Leather. Available online: https://leathercouncil.org/introduction-to-leather/sustainability-of-the-tanning-industry/. (Accessed on October. 12, 2018).

[33] Turker, Duygu, and Ceren Altuntas. "Sustainable Supply Chain Management in the Fast Fashion Industry: An Analysis of Corporate Reports.” European Management Journal 32, no. 5 (October 2014): 837-849. doi:10.1016/J.EMJ.2014.02.001.

[34] KPMG. "Edge of Page - The KPMG Survey of Corporate Responsibility Reporting 2017." The KPMG Survey of Corporate no. 10 (2017). doi:10.1038/nnano.2013.238.

[35] European Commission. EUR-Lex - 32014L0095 - EN - EUR-Lex. Available online: https://eur-lex.europa.eu/legalcontent/EN/TXT/?uri=CELEX:32014L0095. (Accessed on April 9, 2019).

[36] Kuzey, Cemil, and Ali Uyar. "Determinants of Sustainability Reporting and Its Impact on Firm Value: Evidence from the Emerging Market of Turkey.” Journal of Cleaner Production 143, (February 2017): 27-39. doi:10.1016/J.JCLEPRO.2016.12.153.

[37] Bell, Judith. "Doing Your Research Project: A Guide for First-Time Researchers in Education, Health and Social Science". Open University Press, (2005).

[38] Tate, Wendy L., Lisa M. Ellram, and Jon F. Kirchoff. "Corporate Social Responsibility Reports: A Thematic Analysis Related To Supply Chain Management." Journal of Supply Chain Management 46, no. 1 (January 2010): 19-44. doi:10.1111/j.1745493X.2009.03184.x.

[39] Jose, Anita, and Shang-Mei Lee. "Environmental Reporting of Global Corporations: A Content Analysis Based on Website Disclosures.” Journal of Business Ethics 72, no. 4 (March 2007): 307-321. doi:10.1007/s10551-006-9172-8.

[40] Brandenburg, Marcus, and Stefan Seuring. "Quantitative Models for Sustainable Supply Chain Management: Developments and Directions.” European Journal of Operational Research 233, no. 2 (March 2014): 299-312. doi:10.1016/J.EJOR.2013.09.032.

[41] Krippendorff, Klaus. "Content Analysis : An Introduction to Its Methodology". SAGE Publications, Inc., (2018).

[42] Su, Leona Yi-Fan, Michael A. Cacciatore, Xuan Liang, Dominique Brossard, Dietram A. Scheufele, and Michael A. Xenos. "Analyzing Public Sentiments Online: Combining Human- and Computer-Based Content Analysis." Information, Communication \& Society 20, no. 3 (March 2017): 406-427. doi:10.1080/1369118X.2016.1182197.

[43] Erlingsson, Christen, and Petra Brysiewicz. "A Hands-on Guide to Doing Content Analysis.” African Journal of Emergency Medicine 7, no. 3 (September 2017): 93-99. doi:10.1016/j.afjem.2017.08.001.

[44] Elliott, Victoria. "Thinking about the Coding Process in Qualitative Data.” The Qualitative Report 23, no. 11 (2018): 28502861.

[45] Leather Naturally. Leather Naturally - Mission. Available online: http://www.leathernaturally.org/About/Mission.aspx. (Accessed on Jun. 7, 2018).

[46] UNEP. Resource Efficiency | UN Environment. Available online: https://www.unenvironment.org/explore-topics/resourceefficiency. (Accessed on May 7, 2019).

[47] Eurostat. Resource Efficient Europe - Eurostat. Available online: https://ec.europa.eu/eurostat/web/europe-2020indicators/resource-efficient-europe. (Accessed on May 7, 2019). 